\title{
Calderón de la Barca, Pedro. 2009. El árbol de mejor fruto
}

Ed. de I. Arellano. Pamplona-Kassel:

Universidad de Navarra-Reichenberger

(Autos sacramentales completos de Pedro Calderón de la Barca, 65), 226 pp. ISBN: 979-3-937734-65-1.

Rodrigo Faúndez CaRreÑo

Universidad Autónoma de Barcelona. Barcelona, España. rodrigoalberto.faundez@campus.uab.cat

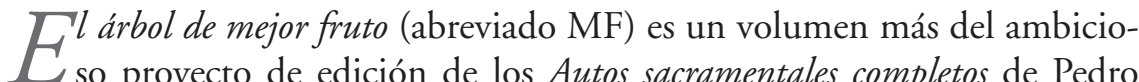
Calderón de la Barca que lleva a cabo el Grupo de Investigación Siglo de Oro (GRISO) de la Universidad de Navarra. Sus objetivos editoriales, de notable interés filológico, ofrecen unos textos fiables, modernizados en su acentuación, puntuación y grafías sin alcance fonético, a partir de un estema que utiliza la totalidad de los testimonios (manuscritos y ediciones) de cada obra. Un completo estudio introductorio, un exhaustivo apartado de variantes y un útil índice de notas complementan y enriquecen las notas explicativas de cada volumen. Sin lugar a dudas, esta variedad de elementos permite suponer una edición definitiva, de gran interés para el especialista, pero también para el lector ajeno a la literatura del siglo XVII, quien puede transparentar, con confianza, el "maravilloso mundo de los autos de Calderón" en su compleja dualidad de ficción literaria y catequesis eclesiástica.

En el presente auto, Calderón propone una alegoría del madero de la Cruz: su sentido redentor y el origen de los siete sacramentos, a partir de una base historial de origen veterotestamentario, que relata la construcción del templo de Jerusalén en tiempos de Salomón y los acontecimientos relativos al viaje de la comitiva de Nacaula de Sabá a Jerusalén: "Sibila soberana / de la gran India Oriental, / emperatriz de Etiopia, / reina invicta de Sabá" (vv. 321-324), encargada, finalmente, de revelar a Salomón la naturaleza del árbol de mejor fruto.

Para comprender el profundo simbolismo que adquiere El árbol de mejor fruto dentro del universo de los autos calderonianos y del teatro religioso 
del Siglo de Oro, los datos que otorga la introducción literaria son de gran utilidad; así, su prolijo estudio comparativo con otros autos ya editados por el GRISO, La humildad coronada (2002), La lepra de Constantino (2008), El primer y segundo Isaac (1997) y El jardin de Falerina (2007), permite armar un rompecabezas que descifra su doble significado jeroglífico: "en cedro, palma y ciprés, / duración, victoria y muerte” (vv. 959-966) y su significado de árbol de "vida y muerte", antitético, que relaciona la cruz de Cristo con el árbol del Paraíso: "antídoto ha de ser primero / porque uno muerte dé y otro dé vida" (vv. 460-461).

Las importantes alusiones al tópico "árbol / madero" en los autos señalados permiten que la edición de I. Arellano refute los postulados de E. Rull sobre la existencia de un presunto ciclo salomónico en Los cabellos de Absalón, la comedia La sibila del oriente y El árbol de mejor fruto. Concede, en cambio, una estricta cercanía entre la comedia y el auto, que considera una segunda versión más "uniforme y precisa" (41), "lógica culminación teológica del ciclo" (43).

Respecto a los personajes, son de un profundo valor historiográfico y documental los datos que el estudio y las notas nos proveen en torno a la reina africana de Sabá, ya que junto con destacar las influencias del relato bíblico (Reyes, 10, 1; Salmo, 71, 10; Isaías, 60, 6; Cantar de los Cantares), las narraciones de Flavio Josefo y de la Patrística en general, se analizan las influencias de los modelos de la tradición clásica y renacentista en Calderón. Un análisis comparativo con la sibila virgiliana de Cumas y su método profético que con hojas de árboles ("canta al destino y confía a las hojas señales y nombres") permite superar la "mala lectura" u omisión en los manuscritos y ediciones previas, en las cuales, para dar sentido al método profético de Sabá, añadían un "libro que desencuadernaba" (v. 388a). La presente edición enmienda, acorde al modelo virgiliano y lee: "Sale Sabá ly va arrojando hojas de árboles al viento]".

La concordancia entre el estudio filológico y el marco de fijación del texto permite que se observen con pertinencia las anotaciones en torno a los recursos petrarquistas que adornan el éxtasis de la Sibila. Una vez que llega a Sión se posa un madero para cruzar, cuando "Más el agradecimiento / a él le toca, pues más flores / debe al contacto pequeño / de tu planta que el abril" (vv. 1792-1794). Motivos florales, reiterados en Calderón, que también propician la discusión teológica en los Alcázares de Jerusalén (vv. 1323-2003), donde Sabá y sus doncellas, a partir de unas "flores falsas y verdaderas" proponen a Salomón una serie de pruebas de ingenio y un acertijo en torno al misterio del "lente / cristal" y su doble efecto: "Dime ahora: 
de esos / dos ramilletes, ¿qué flores / son, miradas a lo lejos, / verdaderas o fingidas?" (vv. 1386-1389).

Una grandilocuente discusión en torno a la Naturaleza Humana y Divina se desata a partir de la observación de las flores, que permite introducir, como desenlace del auto, los principios de la Naturaleza Universal creada por un Dios único: "infinitamente bueno, / santo, sabio y poderoso / incomprensible y inmenso, / de todo principio y fin, / sin fin ni principio, eterno" (vv. 1639-1643); el principio de la Doble Naturaleza Humana: "Pues imagina que el hombre / de varias flores compuesto / que son del alma virtudes / o son flaquezas del cuerpo" (vv. 1684-1686) y el origen inmaculado de Cristo en María, "cristal / lente" en el que Dios "podrá el inmenso / poder hacer que trascienda / la divinidad un bello / claustro virginal sin que / de su cristalino espejo / padezca la integridad / ni lesión ni detrimento" (vv. 1714-1719).

La madurez literaria y doctrinal que ofrece Calderón a través de oráculos y acertijos, junto a las reiteradas escenas de sueño y revelaciones (vv. 1-110, 321-510, 849-998), permite que el inquieto lector se deleite con extensos pasajes que describen un Antiguo Medio Oriente exótico, místico e idólatra. Sus aportes literarios a la actualización del pasado bíblico veterotestamentario, bajo los imaginarios estéticos del Siglo de Oro, permiten que celebremos con entusiasmo la aparición del presente volumen. Pero también, no podemos dejar de mencionar el valor profundamente contemporáneo que adquiere gracias a la modernización de la acentuación, la puntuación y las grafías, que se transforman en verdaderas herramientas al servicio de las artes escénicas en su interpretación del verso y la gestualidad. La multiplicidad de estos aspectos históricos, literarios y teológicos, junto a la posibilidad de una nueva, actualizadora, puesta en escena, hace que la presente edición del auto cobre una vigencia cultural indiscutible. 